\title{
comMentary Towards partnerships in mental healthcare
}

\author{
Sue Bailey \& Richard Williams
}

\section{COMMENTARY ON... UNDERSTANDING 'RECOVERY' \& BECOMING A RECOVERY-ORIENTED PRACTITIONER ${ }^{\dagger}$}

Sue Bailey is President of the Royal College of Psychiatrists, Vice Chair of the Academy of Royal Medical Colleges UK and Professor of Mental Health Policy at the University of Central Lancashire. Richard Williams is Professor of Mental Health Strategy at the Welsh Institute for Health and Social Care, University of South Wales, and an Honorary Professor at the Humanitarian and Conflict Response Institute, University of Manchester. He also works as a consultant child and adolescent psychiatrist for the Aneurin Bevan Health Board, NHS

Wales. Correspondence Professor Sue Bailey, Royal College of

Psychiatrists, 21 Prescot Street, London E1 8BB, UK. Email: sbailey@ rcpsych.ac.uk

${ }^{\dagger}$ See Roberts \& Boardman (2013) and pp. 37-47, this issue.

\begin{abstract}
SUMMARY
We consider key facets of the concept of mental health recovery and how they are reflected in other concepts that run through the emerging focus on public mental healthcare. We widen the scene to portray the niche into which recovery fits and show how it and recent research indicate why psychiatrists should use the social sciences more widely to complement neuroscience.
\end{abstract}

\section{DECLARATION OF INTEREST}

S.B. is President of the Royal College of Psychiatrists.

The two reviews of mental health recovery by Roberts \& Boardman (2013; 2014, this issue) are timely. The principles of recovery are now core to thinking about mental healthcare in the UK and a number of other countries around the world. But our specialty and our mental health services are in major transition. So, we think it critical that practitioners and researchers understand what recovery means for our work and our relationships with patients and their families. Roberts $\&$ Boardman provide an excellent introduction, and we will begin by highlighting key facets of the concept because we see the principles on which recovery rests as vitally important. We are struck by how they are reflected in other concepts that run through the emerging focus on public mental healthcare.

\section{Recovery}

No two people experience illness, disease or disability in the same way. In her Harveian Oration, Heath (2011) quoted the words of Tolstoy: 'No complaint affecting a living being can ever be entirely familiar, for each [...] has his own individual peculiarities and whatever his disease it must necessarily be peculiar to himself'. She then turned to St Luke, the Patron Saint of Physicians, to opine that gentleness is the key to the future of medicine and that it is more important to attempt to identify and support people's resources and capacities for creating health than to concentrate on risk, ill health and disease. So, it was sad to learn, when the College wrote its report on parity of esteem for physical and mental illness (Royal College of Psychiatrists 2013), that some doctors stand wanting in lacking aspiration for their patients and, apparently, being unable to see life beyond illness.

Recovery refers to people living as well as they are able. But it also takes us beyond returning to how we were before we became unwell to our developing new meaning and purposes in our lives as we grow beyond the effects of our health problems. The focus should be on 'salutogenesis' (Antonovsky 1979) rather than pathogenesis. Recovery involves creating new layers of positive identity, amplifying use of personal strengths and social resources, discovering that lived experiences can be assets and not just a vulnerability, and that everyone has something to offer as well as needing support from others (Slade 2010).

Recovery adds educational, human rights and social justice orientations to the responsibilities of society. It collapses the traditional separation between health promotion and illness prevention on the one hand and treatment and rehabilitation on the other. That dichotomy of approach has contributed, albeit unwittingly, to stigmatising people who have mental disorders and possibly excluded mental health professionals from efforts to increase the well-being of populations. But, as Roberts $\&$ Boardman recognise, recovery is not without its critics. Interestingly, both these authors and two critics, Howell \& Voronka (2012), prey social justice in support of their positions. The former pair, wisely we think, encourage us to be aware that our motives in espousing recovery may be misunderstood, erroneously imputed and criticised. 


\section{Horizontal epidemiology, psychosocial care, resilience and social identity}

Close to recovery are the concepts of horizontal epidemiology and psychosocial resilience. The former recognises the centrality to the quality of people's lives of the circumstances in which they live, while the latter recognises that people's personal and collective strengths may surface in times of adversity (Williams 2011; Royal College of Psychiatrists 2012; Cieza 2013). All three concepts turn on trying to alter the circumstances in which people relate, live and work in order to provide them with opportunities to achieve satisfying social identities and derive support from membership of networks and groups.

\section{Horizontal epidemiology}

The concept of horizontal epidemiology gives scientific expression to principles that underpin the recovery and resilience approaches. 'Although it is well known that the burden and costs of [psychiatric] disorders are high, there is evidence that [their] overall, personal, social and economic costs [...] have been underestimated because of the lack of valid and reliable information regarding the full range of psychosocial difficulties that actually shape the lived experience of persons with these disorders [which] affect their quality of life' (Cieza 2013). The premise of horizontal epidemiology is that psychosocial difficulties associated with mental disorders are by no means exclusively determined by diagnosis. It focuses on the experiences of people who have disorders and concentrates on what is relevant to their lives to improve the planning of interventions and their quality of life. In our opinion, horizontal epidemiology provides further evidence to support the recovery approach.

\section{Psychosocial care}

We assert that people who have health problems require psychosocial care that focuses on their wider experiences and needs, alongside highquality mental and physical healthcare. In a forthcoming book chapter, R.W. and a colleague propose two important aspects of planning care for young offenders and young people who use forensic mental health services (Williams 2014). First, recognising and responding to the broad range of psychosocial needs of the young people without limiting that to mental health problems. And second, founding a comprehensive approach to mental healthcare on a solid platform of psychosocial care and education in which people's social, educational and communication needs are considered alongside effective treatments for their mental disorders.

Some readers might object to our dichotomy between psychosocial and mental healthcare because they should be inseparable components of good-quality healthcare - isn't this what Roberts $\&$ Boardman are saying? However, recent highprofile events in the UK show that we cannot yet rely on such a values-led understanding: an objective for the future should be to remove the need for this distinction.

\section{Psychosocial resilience}

Psychosocial resilience explores a preventive dimension concerning what enables people to bounce back from distress in the face of many differing adversities. Resilience draws on the personal and collective resources that people and their peers mobilise to avoid becoming more affected than they might otherwise. The Journal of Child Psychology and Psychiatry focused its annual research review for 2013 on resilience in child development. The editors point to neurobiological and socioecological perspectives from among many disciplines that contribute to our growing understanding. They portray resilience as the process of harnessing biological, psychosocial, structural and cultural resources to sustain wellbeing (Panter-Brick 2013).

\section{Social identity}

Personal factors are important for resilience, but we also highlight evidence from social science that should influence what constitutes psychosocial and mental healthcare (Williams 2011). We are in good company (Priebe 2013). Tol et al (2013) raise striking resonances between the notions of horizontal epidemiology, recovery and resilience when they conclude that the 'body of knowledge supports a perspective of resilience as a complex dynamic process driven by time- and contextdependent variables, rather than the balance between risk and protective factors with known effects on mental health'. We emphasise the importance of the social sciences to understanding all three concepts. Research has demonstrated the substantial effect sizes of social support on physical and mental health (Jetten 2012). It consists of social interactions that provide people with actual assistance, but also embed them in a web of relationships that they perceive to be caring and readily available in times of need.

We see recovery and resilience as related and overlapping concepts albeit with differing focuses for action. They share strikingly similar principles. 
Roberts \& Boardman say that recovery is based on hope, control and opportunity. Resilience is based on hope, agency and social support (Williams 2011). The extant mental health approaches to resilience and recovery take in what Omand (2010) might call third-degree resilience through people endeavouring to develop adaptability.

We interpret Roberts \& Boardman as teaching us just how important are patients' shared social identities to their well-being and their ability to live as well as they are able. Social identity is based on views we take into ourselves of who we are on the basis of our membership, however loose or tight, of a range of social groups. Shared social identity is the basis of productive social interactions, including communication, family life, social support, leadership, motivation, cooperation and trust.

There is evidence to support our contentions about resilience, but, by extension, the social identity approach seems to us to be highly applicable to the understanding and development of the recovery approach. Arguably, the social identities of patients and relatives in Mid Staffordshire (Francis 2013) and the residents of Winterbourne View and their families (Department of Health 2012) were deeply affected by their hugely aversive experiences and there was too little positive sharing of identities between staff and patients or residents.

\section{Co-production}

A balanced plan for effective psychosocial and mental healthcare requires us to learn from a range of perspectives about how best to protect the mental health of populations and optimise care offered to people who have mental health problems. We should take full account not only of risk and protective factors, but also of time, context, and collective and horizontal epidemiological factors. This requires us to enable new alignments between patients, the people who provide their support and practitioners in services. If effective, these alignments might promote co-productive relationships involving the public, practitioners and policy makers.

Co-production goes well beyond the boundaries of mental healthcare. In its People Powered Health programme, Nesta UK makes the case for changing the ways in which all healthcare is organised by showing how the very best scientific and clinical knowledge can be better combined with the expertise and commitment of patients (Horne 2013). Nesta advocates:

- changing consultations to create purposeful, structured conversations that combine clinical expertise with patient-driven goals and build networks of support

- commissioning new services that provide more than medicine to complement clinical care by supporting long-term behaviour change, improving well-being and building social support networks

- patients and professionals co-designing pathways that focus on long-term outcomes, recovery and prevention.

Again, there are striking overlaps with the principles presented by Roberts $\&$ Boardman.

\section{Transition}

Roberts \& Boardman (2013) say, 'Some have sceptically seen [recovery] as little more than appropriation and re-labelling of existing "good practice" principles', whereas 'Others see it as a radical and challenging approach'. We can understand this spectrum of reaction and the overlap with Good Medical Practice (British Medical Association, 2013). We see similar implications for the quality, culture and values of our services and professional behaviour reflected in each of the related concepts. In our opinion, recovery, psychosocial resilience and co-production each depend on people's social identities: each describes attitudes to social processes and ways of living that affect what people can achieve.

The challenge for the next 10 years is achieving values-based and evidence-informed mental healthcare in which practitioners and researchers are partners with people who use services. We must spread our learning to take into practice developments in the social sciences. We must use understanding of social identity and social networks because these are the sources of social support that can have substantial effect sizes (Jetten 2012). Failing to follow this route could diminish gains for mental healthcare from the rich developments in neuroscience.

We believe that people who live with all health conditions should be central to the planning and delivery of their care: partnerships within delivery systems can help to reduce inequalities. This virtuous, coordinated delivery system is radical: it requires us to revisit relationships with our colleagues across healthcare. If we are to promote people's mental health, while mitigating and moderating the risks of ill health and reducing blockages to recovery, we also require values-based approaches to better recognising and actively harnessing the social determinants of health.

This is why the concept of recovery is so important. Becoming a recovery-oriented practitioner in the post-Francis, post-Winterbourne era requires 
us to turn principles into practice: this agenda fits well with delivering safe care with compassion and dignity. As we look at the 289 recommendations of the Francis report (Francis 2013), we cannot but reflect on the improvements that might come from all doctors becoming recovery-oriented practitioners. That would open up the legitimacy of them seeing patients in a whole context and not diminish their unique skills as doctors.

A key challenge is how we embed this approach across our training and in day-to-day practice. This propels us to improve the psychosocial safety of the environments in which all practitioners work and the leadership and peer support that practitioners require if they are to build on their strengths and sustain their resilience (Edmondson 2003). Surely, the values that we espouse for patients apply to staff of health services too? We think it unlikely that our ambitions will succeed unless greater attention is paid to developing, leading and supporting staff to enable them to create healthy environments and work in partnerships. The importance of these matters is raised during this time of austerity: peer support for practitioners may look costly, but can we afford to ignore it?

\section{Concluding remarks}

It is not uncommon for people with severe mental health problems to live lives that are centred on contact with fellow patients, staff and mental health facilities. We applaud Roberts $\&$ Boardman. They remind us to look beyond illness and on into the hopes and aspirations of patients as multifaceted human beings. As they point out, people live in society, not in mental health services. Recently, there have been major steps forward in programmes for implementing recovery and improving collaboration with nonstatutory organisations. These opportunities are to be embraced rather than feared: the recovery approach and better collaboration should be securely embedded in services across the country.

We highlight the importance of partnerships - partnerships between: neuroscience and social sciences; values-based and evidence-informed practice; people and the social groups and networks that can and should support them; and between patients and practitioners. We must improve the psychosocial safety of working environments, especially in a climate that remains risk averse rather than promoting positive risk-taking. We encourage Roberts $\&$ Boardman to assist with achieving what they and we desire by advising us about how each of these processes might be better harnessed and integrated within healthcare.

\section{References}

Antonovsky A (1979) Health, Stress and Coping. Jossey-Bass Publishers. British Medical Association (2013) Good Medical Practice. BMA.

Cieza A (2013) PARADISE: Psychosocial Factors Relevant to Brain Disorders in Europe. European Commission (http://ec.europa.eu/ research/health/medical-research/brain-research/projects/paradise_ en.html).

Department of Health (2012) Transforming Care: A National Response to Winterbourne View Hospital. Department of Health Review: Final Report. Department of Health.

Edmondson A (2003) Managing the risk of learning: psychological safety in work teams. In International Handbook of Organizational Teamwork and Co-operative Working (eds M West, D Tjosvold, Smith K). John Wiley \& Sons.

Francis R (2013) Report of the Mid Staffordshire NHS Foundation Trust Public Inquiry. TSO (The Stationery Office)

Heath I (2011) Divided We Fail: The Harveian Oration 2011. Royal College of Physicians.

Horne M, Khan H, Corrigan P (2013) People Powered Health: Health for People, by People and with People. Nesta.

Howell A, Voronka J (2012) Introduction: the politics of resilience and recovery in mental healthcare. Studies in Social Justice, 6: 1-7.

Jetten J, Haslam C, Haslam SA (2012) The Social Cure: Identity, Health and Well-Being. Psychology Press.

Omand D (2010) Securing the State. Hurst.

Panter-Brick C, Leckman JF (2013) Editorial commentary: resilience in child development - interconnected pathways to wellbeing. Journal of Child Psychology and Psychiatry, 54: 333-6.

Priebe S, Burns T, Craig TKJ (2013) The future of academic psychiatry may be social. British Journal of Psychiatry, 202: 319-20.

Roberts G, Boardman J (2013) Understanding 'recovery'. Advances in Psychiatric Treatment, 19: 400-9.

Roberts G, Boardman J (2014) Becoming a recovery-oriented practitioner. Advances in Psychiatric Treatment, 20: 27-47.

Royal College of Psychiatrists (2012) Recovery and Resilience: Our President's New Campaign. Royal College of Psychiatrists (http://www. rcpsych.ac.uk/about/campaigns/recoveryandresilience.aspx). Accessed 22 Oct 2013.

Royal College of Psychiatrists (2013) Whole-Person Care: From Rhetoric to Reality. Achieving Parity between Mental and Physical Health (Occasional Paper OP88). Royal College of Psychiatrists.

Slade M (2010) Mental illness and well-being: the central importance of positive psychology and recovery approaches. BCM Health Services Research, 10: 26

Tol WA, Song S, Jordans MJD (2013) Annual research review: resilience and mental health in children and adolescents living in areas of armed conflict - a systematic review of findings in low- and middle-income countries. Journal of Child Psychology and Psychiatry, 54: 445-60.

Williams R, Drury J (2011) Personal and collective psychosocial resilience: implications for children, young people and their families involved in war and disasters. In Children and Armed Conflict: Cross-Disciplinary Investigations (eds D Cook, J Wall, P Cox). Palgrave Macmillan.

Williams R, Kemp V (2014) Psychosocial resilience, psychosocial care and forensic mental healthcare. In Adolescent Forensic Psychiatry (eds S Bailey, P Tarbuck). Cambridge University Press. In press. 